\title{
Vesico-vaginal fistula of obstetric origin inaccessible vaginally: a case report and literature review
}

\begin{abstract}
Summary
A case Vesico Vaginal Fistula VVF of origin inaccessible obstetric vaginally. The pathogenesis of this fistula seems classic, but the delay between the initial event and the appearance of the fistula seems too short. Adolescence and the remoteness of the health structure with the recipient were not found among the contributing factors. In front of the operating difficulties by track low, a conversion by a high track has been necessary. The surgical technique used was a fistulorraphie revilement by the banks without resection The treatment of fistula has been undertaken only one month after its occurrence, without any particular complication occurring. The success of the surgical treatment of obstetric fistula depends not only on the dexterity of the surgeon, but much of the quality of care pre, PER and post-operative.
\end{abstract}

Keywords: obstetric fistula, inaccessible track low
Volume 2 Issue I - 2018

\author{
Mbongo JA,' Ngabogo A,' Mahoungou F,' \\ kimbouala S,' Omock H,' Tebeu PM, ${ }^{2}$ Itoua \\ C,' Iloki LH' \\ 'Service de Gynécologie Obstétrique CHU de Brazzaville, \\ Congo \\ ${ }^{2}$ Service de Gynécologie Obstétrique CHU de Yaoundé, \\ Cameroun
}

Correspondence: Jean Alfred Mbongo, Service de Gynécologie Obstétrique CHU de Brazzaville BP 32, Congo, Tel +242 0553198|2,Email mbongojalf@gmail.com

Received: December 29, 2017| Published: February 12, 2018

\section{Introduction}

Obstetric fistula, a complication of dystocic labor neglected in the social and developmental context, shows the progress made in improving health status in developing countries. ${ }^{1}$ The difficulty of treating vesico-vaginal fistulas is well known and the proposed repair techniques are numerous. ${ }^{2}$ The choice of the way of approach is not unequivocal, because the best way is that the comfort operatories. ${ }^{3} \mathrm{We}$ report a case of vesico-vaginal fistula of class IV; no work took place nevertheless in a haplite center, at a parturient of mature age. The operating difficulties encountered, and the early delay between the occurrence of fistula and the surgical treatment realize us a particular case.

\section{Observation}

Mrs. x Lesly, 32 years old, seamstress by profession, living in a de facto and living Brazzaville, admitted in the Obstetric Gynecology Department of the Brazzaville Teaching Hospital, on June 15 $5^{\text {th }}, 2016$ for urinary incontinence evolving for 2 weeks. Dance has a history of ovarian cystectomy in 2012. All is G2P2, with 1 child living 12 years, and 1 stillborn. A month ago, you have a long time for your business, 40 years old, and you are giving an indication of your choice and commitment. The indication-extraction period was extended by approximately 5 hours due to logistical problems. Cesarienne had allowed the extraction of a fetus dead-ne macerated male sex weighing 3500 grams. And by operatory it was a badly flipped head. The operational suites were simple. One week after discharge from the hospital, urinary incontinence characterized by permanent staining of underwear and lingerie justifying consultation in the Obstetric Gynecology Department of the University Hospital of Brazzaville. After the methylene blue test, the diagnosis of vesico-vaginal fistula of obstetric origin is retained. It was a fistula affecting the neck of the bladder, about 2 centimeters of the diameter, with friable margins. The operative indication was posed.

A evaluation preoperative, to the palpation fistula, in accordance with the private sector, was tested by the methylene confirming the diagnostic vesico-vaginal fistula. Preoperative assessment, hemostasis, glycemia fasting and creatinine were normal. We noted a moderate anemia (hemoglobin at $9.2 \mathrm{~g} / \mathrm{dl}$ ). She was of the blood group A positive. On June 22, 2016, the fistula cure is decided. Let the patient have a place and a gynecological position, with the seat overflowing by 20 centimeters the edge of the table. We practiced the asepsis of the operating fields by pyridone iodine badoning of the vulva, the vagina and the abdomen. The orientation of the exposure was obtained by exposure of the spread and semi-elongated thighs. Exposure of the vulva was obtained by attachment to the threads. The draping was done with sterile linen. Peri-fistular infiltration has not changed. And per opera ration, the examination under anesthesia, then conversion and general anesthesia, shows a trigonal fistula of 3 centimeters, with a bladder hanging fortifying the posterior face of the pubic symphysis and not surgically accessible vaginally.

The attempt to cure suckling fistula vaginally has been futile. The right medio-lateral episiotomy performed to optimize the chance of success did not pass the game. It was a class IV vesicovaginal fistula, inaccessible vaginally. The high way was made by Pfannenstiel incision, and approaching the pubic symphysis behind without peritoneotomy. After bladder tracing and cystotomy, urethral intubation was performed with nasal gastric probe number 6 . Vesicovaginal duplication was impossible. Due to the access, we decide on a fistulorraphy by raveling the banks without resection. The bladder was sutured on its posterior wall with trans vesicle over lock tied to the vicryl $2 / 0$ and a main plane and a reinforcement plane, on anterior with on again and 2 plan vicryl $2 / 0$. The tightness test was performed on the methylene blue test after the first anterior bladder. We performed the episiotomy and vaginal suture and drainage of the Retzius space. And by appointment, you will be able to make an appointment immediately after completing your contract. You will be notified as soon as possible. Read per sanguines were estimated at $700 \mathrm{ml}$.

This is a good idea for 5 days and the Foley is 21 minutes. And postoperative, antibiotic prophylaxis of 2 years (efritaxone 2 grams / day and gentamycin $160 \mathrm{mg} /$ day) was administered, combined with anticoagulants (levox0, 4ml / day); Numeric acorns on demand (paracetamol grams and pain cases). Parenteral hydration 
was required with an early oral relay starting up to 6 liters per 24 hours because of the patient's good tolerance. At the thirteenth is a postoperative, supernumerary launches of perineal lauritis and urine frankly suspicious making suspect a pyuria but the evolution was quickly favorable probabilistic antibiotic therapy. As a precaution, a communication for behavioral change was also made under the themes of no sexual intercourse before 6 months, no pregnancy before 2 years, hence contraception for 2 years. Formal prohibition of subsequent vaginal delivery.

\section{Discussion}

The patient was 32 years old with paid employment, living in urban areas, consulted directly with an appropriate health facility. You have the idea that you will be able to assimilate your right to a set of responses, responsible for an indication of the censorship, read the authors' aspects of contrast, and you will be aware that you have a fistula obstetrical occurs especially at home. Adolescents, with whom we find the notion of early marriage, traditional practices that, are not good and sanitary education [1.4]. While some authors note that the majority of patients with fistulas are referred to the care services of the interior of the country and think by analogy that obstetric fistula, retreats from the capital to the interior of the country [5], in our case, a level III health service, the capital is concerned. The aspect of prolonged ischemic compression of the pelvic planer by the fetal head, which is enclosed during labor, can be explained by the notion of non-commitment to complete dilatation of an incorrectly flipped fetal head; this corroborates with the literature data on obstetric fistula [1.6]. Dancing note observation, it's a good idea; it's supposed to be a breakthrough, because of the interruption of music, the singing of the music, the dance of the music, and the entourage of the film. A pressure ulcer would be formed secondarily explaining the subsequent occurrence of the fistula.

Despite the precautions of asepsis and the addition of an antibiotic prophylaxis instituted according to the usual protocol, ${ }^{7}$ the perineal sutures and one pyuria were released. The releasing of the anal sphincter, with stool delivery during the procedure could and be the cause. It is recommended that you receive a pre-infection of the examinations of the urine tests, the test of syphilis, the lesions of HIV and the hepatic viral B. ${ }^{7}$ Treatment of the fistula was undertaken only one month after onset, without any particular complication. In current practice a period of 3 months is required before any obstetric fistula surgery. ${ }^{1-8}$ The low way has been at the beginning privileged, the difficulties met despite dexterity and surgeon expertise pushes to a reconversion in a high way. According to Dupont et al., Who does the abortion of unprecedented excellence, allowed me to have a cellular apprenticeship. ${ }^{9}$ Some authors reported that they had received an awareness of efficacy in the use of vaginal and decubitus ventral. ${ }^{10}$ But, it is conventional to recognize that if no technique and parity on in experimentation, the choice of the vaginal route old abdominal will be made and function of the experience of the surgeon, the location of fistula and the extent of the lesions. ${ }^{7}$ Some authors have established a prognostic classification of obstetric fistulas for a better appreciation of the possibilities of success.

Therapeutic. ${ }^{11}$ The operative technique used was fistulorraphy by bank reversion without resection. The difficulty of treating vesicovaginal fistulas is known and the techniques of repair proposed are numerous. ${ }^{2}$ Despite complications without gravity postoperative, healing is possible for our patient. Operative success depends on the reception of inflammatory phenomena and the healing of the fistular tissue within 10 to 12 weeks. ${ }^{1}$ The success of surgical treatment of obstetric fistula depends greatly on the quality of postoperative care. For some authors, peripheral neurological involvement has always been underestimated in the management of obstetric fistulae of vesico-vaginal fistula, fistula is only apparent manifestations of "neuro-vesical damage" in the remain determinants in the prognosis. They explain for a large part the frequency of therapeutic failures. ${ }^{5}$

\section{Conclusion}

The epidemiological factors of obstetric fistulas can be nuanced, the pathogen remains the same, and despite the multitude of surgical techniques, the expertise of surgery is essential.

\section{Acknowledgements}

None.

\section{Conflict of interest}

The author declares no conflict of interest.

\section{References}

1. Said Mandouni, Mouad Nouri, Abdelltif Koutani, et al. Obstetric vesicovaginal fistulas, About 114 cases. Progress in Urology. 2001;11:103-108.

2. Leach GE, Trocham BA. Surgery for vesico-vaginal and uretthrovaginal fistula and urethral diverticulum In: Wash PG, Retik AB, editors. Camppbell's Urology. 7th edition. Philadelphia WB Sanders; 1998. p. 1135-1153.

3. Dupont MC, Razs. Vaginal approad to vesico vaginal fistula repair. Urology. 1996;48:7-9.

4. Harouna YD, Seibou A, Maikano S, et al. La Vesico-vaginal fistula of obstetric cause: Survey of 52 women admitted to fistula village. Med Afr Noire. 2001;48(2):55-59.

5. Anoukoum T, Folligan F, Dosseh D, et al. Vesico-Vaginal Fistula (FVV) in Chu-Tokoin: analysis of 39 observations. 2008;10(1):1-4.

6. Mensah A, Mamadou BA, Seringne Mogueye Gueye, et al. Neurological aspects of vesico-vaginal fistula of obstetric origin. Progress in urology. $1996 ; 6: 398-402$

7. Obstetric fistula. Guiding Principles for Clinical Management and Program Development. World Health Organization. 2009. p. 1-81.

8. Benchekroum A, El Alj HA, Sayegh H EI, et al. Les fistules vesicovaginales: A propos de 1050 cas. Annales d'Urologie. 2003;37(4):194198.

9. Dupont MC, Raz S. Vaginal approach to vesicovaginal fistula repair. Urology. 1996;48(1):7-9.

10. Sekou Guiramy, Ibrahima Bah, Mamadou Bobo Diallo, et al. Cure de fistule vesico-vaginale par voie basse en decubitus ventral (34 CAS). Progrès en Urologie. 1994;4:561-562.

11. Tebeu PM, Ngassa Meutchi G, Noa Ndoua CC, et al. Tebeu'S prognostic classification of obstetrique fistula according to anatomopathologic variables from the university Teaching Hospital, Yaounde Cameroon. Int Jounal of Reproduct Medicin and gynecology. 2017;3(2):28-33. 